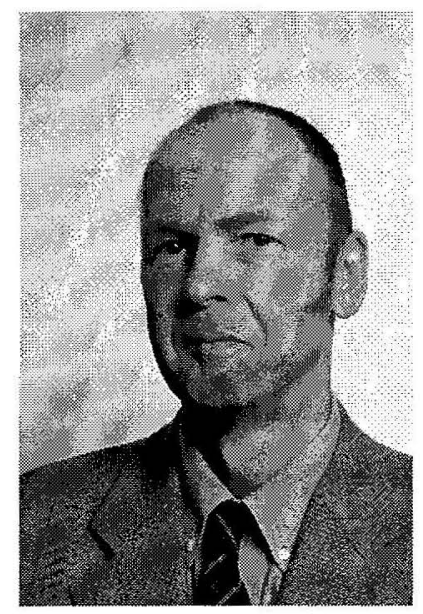

\title{
MOVED BY THE COMPANY - EMPLOYEE RELOCATION AND REGIONAL MIGRATION
}

\author{
Martin Perry ${ }^{1}$ \\ Labour Market Policy Group \\ Department of Labour
}

\begin{abstract}
Organisational labour migrants are those being moved by their employer typically in response to organisational rather than labour market characteristics. Employment continuity and subsidised relocation costs give them advantage over other migrants. Evidence from a survey of large employers in New Zealand indicates that this form of migration has reduced but that it generates a distinctive migrant flow.
\end{abstract}

\section{Introduction}

It has been argued that theories to explain internal migration in industrial economies need to reflect the importance of internal labour markets (Salt, 1990). Models of internal migration have tended to assume movement reflects an individual's evaluation of employment opportunities in differing locations. In contrast, employment concentration in national and transnational organisations has given rise to the organisational labour migrant. These labour migrants change residence but not employer. Consequently they avoid many of the barriers that may impede independent migrants and may move for organisational reasons rather than location characteristics or career advantage.

The contribution of internal regional migration to labour market adjustment in New Zealand has generated alternative interpretations. Large numbers of people move but the net migration flows are small (Bedford and Goodwin, 1997). Given persistent regional variations in unemployment, one researcher has argued that internal migration is too low (Poot, 1986). More recently, others have argued that the working population is highly migration responsive to regional employment change when migration is compared with other labour market adjustments (Choy et al., 2002). Resolving these contrasting interpretations depends partly on understanding the organisational contribution to migration.
Evidence in the UK indicates that by 1981 , organisational labour migration accounted for over half of inter-regional relocation by employed persons (Salt, 1990, p54). It has also been claimed to be a significant aspect of migration within Australia (McKay and Whitelaw, 1977). In New Zealand, the largest 100 employers account for a disproportionate share of employment outside of Auckland (New Zealand's largest region) and the neighbouring region of Northland (Table 1). Movement within these organisations may, therefore, be an important share of total labour migration if internal labour markets integrate separate locations. On this basis a survey was undertaken to ascertain its contemporary importance in New Zealand. The results suggest that it is a much smaller part of total migration than indicated in the earlier claims from UK and Australian experience.

\section{Survey of Organisations and Labour Migration}

Relocation data were obtained through interviews with human resource managers of 50 organisations. The organisations were selected from rankings of private and public sector organisations (New Zealand Management, 2001; State Services Commission 2001). The largest organisations identified in these sources that were known to have employment in more than one region were approached for interviews. The 50 successful requests came from a total of 89 organisations.

\footnotetext{
${ }^{1}$ The views represented in this paper are the author's own and should not be taken to represent the views of the Department of Labour.
} 
Table 1 Contribution of the largest 100 employers nationally to regional employment

\begin{tabular}{|l|c|c|}
\hline \multicolumn{1}{|c|}{ Region } & $\begin{array}{c}\text { Share of regional employment } \\
\text { provided by the top 100 } \\
\text { employers nationally (\%) }\end{array}$ & $\begin{array}{c}\text { Difference between region's } \\
\text { share of national employment } \\
\text { and top 100 employment (\%) }\end{array}$ \\
\hline Northland & 12.9 & -9.9 \\
Auckland & 19.0 & -13.0 \\
Waikato & 19.4 & 10.3 \\
Bay of Plenty & 14.0 & 8.4 \\
Gisborne & 12.1 & 11.1 \\
Hawke's Bay & 20.1 & 16.4 \\
Taranaki & 20.4 & 17.9 \\
Manawatu-Wanganui & 22.9 & 17.3 \\
Wellington & 24.4 & 11.8 \\
West Coast & 9.3 & 8.5 \\
Canterbury & 19.9 & 6.5 \\
Otago & 20.7 & 15.8 \\
Southland & 23.9 & 21.4 \\
Tasman & 9.5 & 8.4 \\
Nelson & 30.1 & 29.0 \\
Marlborough & 20.7 & 19.6 \\
\hline
\end{tabular}

Source: Statistics New Zealand (2002) New Zealand, Census of Population and Dwellings 2001,

Regional Summary volume two

It is possible that employee relocation may be disproportionately high among participating organisations. Of the 39 unsuccessful requests, about half used a lack of employee relocation as a reason for declining. Estimates of none to less than five moves a year were given, although a lack of definite information was also admitted to. The 50 respondents are broadly representative of the 100 largest multi-region employers identified from official business demography statistics (Table 2). Business services, community services and education and health are under-represented in the survey sample while finance and utilities and construction are over-represented. The total employment (full time equivalents) in the top 100 organisations was almost 272,000 compared to 119,249 in the sample, indicating a bias to smaller organisations. Consequently the final sample may not over-estimate the extent of organisational labour migration when estimates are projected across all sectors.

The first part of the survey involved face-to-face meetings with human resource managers in the organisation's head office plus three telephone interviews with respondents who were unwilling to participate in a face-to-face meeting. Selected respondents were then requested to complete a profile of relocation over the prior 12 months to confirm and augment the information obtained in the interview. A willingness to supply the data, based partly on the accessibility of the information sought, influenced the selection of organisations for the second part of the study. The 15 profites include three cases where a form was completed without a prior faceto-face meeting. Both parts of the survey covered domestic and international relocation although this paper discusses domestic relocation only.
Relocation was defined as moves between work-sites requiring a change in residence for an expected period of at least 12 months. Interviews probed connections between an organisation's commitment to an internal labour market and the frequency of relocation. No specific hypothesis was generated for the investigation in view of the lack of prior information about employee relocation in New Zealand and the wish to use the survey to gather information as widely as possible.

Prior conceptualisation recognised three potential types of organisational labour migration:

(i) Job relocation arising from a change in the location of work that employees follow.

(ii) Vacancy relocation to fill a position vacated by another employee or produced through changes in activity or work organisation at the site with the vacancy.

(iii) Employee-initiated relocation through an employee request to be relocated to another work location.

Employers have influence over each type of move. The distinction is relevant to explain relocation frequency and how it may change.

Information relating to the incidence and explanation of organisational labour migration in the sample organisations is summarised in four stages. First, the extent of labour relocation is outlined, distinguishing the three main types of movement identified above and the types of employee typically moved. As well as the incidence of relocation, organisational assessment of the acceptability of the present rate of movement is explained. Second, the reasons organisations relocate employees are summarised. Third, changes in the 
frequency of movement are discussed. Fourth, a detailed profile of employees relocated is reviewed using data supplied by 15 organisations.

Table 2 Employment distribution in the 100 largest employers and the sample respondents

Table 2a Sector comparison

\begin{tabular}{|l|c|c|}
\hline \multirow{2}{*}{ Sector } & \multicolumn{2}{|c|}{ Distribution of employment (\%) } \\
\cline { 2 - 3 } & $\begin{array}{c}\text { Largest employers in 2001 } \\
\text { (n=100) }\end{array}$ & $\begin{array}{c}\text { Sample organisations } \\
\text { (n=50) }\end{array}$ \\
\hline Primary & 0.81 & 2 \\
Manufacturing & 23.16 & 22 \\
Utilities \& construction & 2.21 & 10 \\
Wholesale \& retail & 14.10 & 14 \\
Transport & 5.16 & 6 \\
Accommodation \& restaurants & 1.26 & 2 \\
Communications & 7.19 & 6 \\
Finance & 9.33 & 20 \\
Business services & 7.02 & 4 \\
Government & 10.08 & 10 \\
Education \& health & 6.75 & 0 \\
Community services & 12.93 & 4 \\
\hline
\end{tabular}

Table 2b Employment size profile

\begin{tabular}{|l|c|c|}
\hline \multirow{2}{*}{ Employment range } & \multicolumn{2}{|c|}{ Number of organisation } \\
\cline { 2 - 3 } & Largest employers 2001 & Sample organisations (\%) \\
\hline over 5000 & 10 & $9(18 \%)$ \\
$2000-4999$ & 46 & $10(20 \%)$ \\
$1000-1999$ & 38 & $9(18 \%)$ \\
less than 1000 & 6 & $22(44 \%)$ \\
Total & 100 & 50 \\
\hline
\end{tabular}

Source: Business Demography Database, Department of Statistics

\section{Relocation Frequency}

Annual rates of relocation are small when expressed as a share of the total employees (Table 3). It amounts to around 1.2 percent of the total workforce of the sample organisations, involving 1480 employees. Relocation increases among employees that organisations wish to be mobile. Around a quarter of total employees are in job categories that employers believe justify relocation to fill vacancies. Among these employees, around 5 percent of potentially relocated employees are relocated annually. This typically involves senior to middle managers, sales staff and technical specialists.

The organisation with the highest rate of relocation moved over 400 staff in 12 months out of a total workforce of 7000. This gives a rate of movement that is around five times the sample average. At the other extreme, three organisations report no relocations. Two of these are public sector organisations. In both cases human resource management is devolved to regional offices. Some relocation could occur without corporate office knowledge but respondents expressed confidence that relocation was not important. Although both have large national workforces they avoid relocation either by relying on short-term secondments or short-distance transfers. The third organisation without relocation is a co-operative of individually-owned and operated businesses.

Vacancy relocation accounts for most organisational labour migration with job relocation and employeeinitiated movement of equal secondary importance. The unclassified relocation reflects the difficulty respondents had in distinguishing types of relocation. A difficulty is that a human resource manager in the corporate office may not be familiar with the origin of the relocation. Apportioning some moves to a single category is a second source of difficulty. For example, the boundary between employee-initiated and job relocation may be unclear where employees argue that their job is more effectively performed in another location. These problems aside, it is evident that vacancy relocation dominates movement. 


\begin{tabular}{|l|r|}
\hline \multicolumn{1}{|c|}{ Estimates of } & \\
\hline Total employees & 119,249 \\
Number of employees organisations are potentially willing to relocate & 28,350 \\
Number of employees relocated in the last 12 months & 1,480 \\
\hline Number of organisations with annual employee relocation : & 1 \\
- over 100 persons & 9 \\
- 50-99 & 22 \\
- 10-49 & 15 \\
- less than 10 & 3 \\
- no relocation & \\
\hline Number by type of relocation: & $922(62.3 \%)$ \\
- vacancy relocation & $215(14.3 \%)$ \\
- job relocation & $211(14.5 \%)$ \\
- employee initiated & $132(8.9 \%)$ \\
- unclassified & \\
\hline
\end{tabular}

None of the organisations interviewed monitored relocation. To respond to the survey, data were obtained most frequently from a record of relocation assistance paid. Organisational policies with respect to the payment of assistance thus influence the reported relocation. With the exception of two organisations, employee-initiated moves are generally not eligible for relocation assistance. Most organisations provide relocation expenses to a person voluntarily applying for a vacancy but some see this as another form of employee-initiated move and make assistance discretionary to the individual circumstances.

A comparison of relocation by two organisations in the same industry gives an impression of the extent of underrecording when measuring relocation from the payment of removal expenses. One of the organisations has a policy of not funding vacancy relocation and the other does. Both have employment with concentrations in Auckland and Wellington plus a large number employed in a national branch network. Both organisations have shifted corporate functions and business unit management from Wellington to Auckland, although this shift is ongoing in the organisation that does not fund vacancy relocation. The organisation funding vacancy relocation reported 55 vacancy relocations over 12 months out of a total workforce of around 4500 . The organisation not funding vacancy relocation reported 3 vacancy relocations over a similar 12 -month period out of a total workforce of around 3000 .

It is possible that not paying expenses reduces participation in relocation. Otherwise on a proportional basis, actual vacancy relocation may be close to 40 in the organisation not paying expenses. In addition, as neither organisation provides assistance for employee-initiated relocation, there is a further under-recording.

The estimate of relocation frequency obtained captures the assisted component of all organisational labour migration. No attempt is made to adjust this estimate for differences in relocation policies but it can be concluded that actual organisational labour migration among the 50 surveyed organisations is probably significantly higher than the assisted migration.

Most organisations are satisfied with their present rate of relocation. One organisation (a retail chain) reported that the rate of relocation was too high and seven indicated that it is lower than they would like. Two further respondents were uncertain but tended to believe more movement would be helpful.

Organisations believing mobility is too low tend to have employment in locations outside main centres. The assessment reflects difficulties attracting staff away from or to specific locations rather than a general unwillingness to move, although there is one organisation that believes this to be the case. The locations identified as problematic tend to be individual to the organisation, partly reflecting the particular mix of locations operated in.

The organisation reporting that it has too much relocation believes the frequency of movement is disrupting efforts to manage career development and staff succession. The respondent argues that the high rate of labour turnover is a consequence of a national shortage of experienced managers in their area of business rather than of influences under the organisation's own control.

\section{Reasons for Relocation}

Employers have a variety of reasons for relocating staff (Table 4). These organisational motivations are one reason for distinguishing employee relocation from other types of labour migration. It generates movement that reflects organisational priorities and resources even when combined with an employee preference to make the move. 
Providing career development and ongoing employment is the most frequent motivation for supporting relocation. This motive exists because locations give experience in different aspects of a job or, more usually, because of limited opportunities in a single location.

Table 4 Organisational reasons for relocating employees $(n=30)$

\begin{tabular}{|l|c|}
\hline \multicolumn{1}{|c|}{ Motivations for relocating employees } & $\begin{array}{c}\text { Number of } \\
\text { organisations citing } \\
\text { this influence }\end{array}$ \\
\hline Maximise continuity of employment \& career development & 28 \\
Promote organisational flexibility & 20 \\
Fill skill/recruitment gaps & 15 \\
Promote organisational integration \& uniform work practices & 15 \\
Accommodate employee requests & 12 \\
Job relocation & 11 \\
Fill gaps in hard to recruit locations & 8 \\
Minimise external recruitment & 8 \\
Induction of new recruits & 1 \\
\hline
\end{tabular}

Note: 1 . Respondents were asked to identify up to three influences from the list supplied

Relocation to fill skill gaps and recruitment difficulties identifies movement that would not happen if external recruitment were an option. Retail managers and sales representatives in customer service industries were referred to as occupations generating high rates of relocation. A shortage of persons willing to enter these professions and the importance of company allegiance and knowledge as the basis for promotion explains the difficulty recruiting externally for these jobs.

Other important motives are to assist organisational flexibility and integration. Relocation helps ensure that the distribution of skills and experience matches staff turnover and market changes and can help to standardise work processes. As goals in themselves, organisational motivations may be hard to realise where promotion is not part of the outcome for relocated employees. Other motives are identified by a small number of organisations. These confirm the secondary role of job relocation and employee requests to move.

The diversity of motivations revealed partly reflects how hard the organisation needs to work to secure movement. Where there is staff interest in relocation, multiple objectives may be secured without the organisation having to specifically plan for them.

\section{Changes in Relocation Frequency}

Movement over the last 12 months prior to the survey was generally viewed as representative of recent experience and that expected in the near future. Most organisations able to make a longer term historic comparison (five years or more), indicate that the frequency of relocation has declined. This decline was especially significant in those organisations with a national branch network of customer service and sales offices. Changes in work and organisational design as well as in the perceived ability of the employer to direct relocation are given as reasons for the decline. The experience of banks illustrates how these processes have reduced relocation.

Banks traditionally relocated branch staff as part of the process of developing staff and distributing experience between places. Employees were expected to see relocation at the employer's instigation as necessary for promotion. Lending authority was delegated to branch staff according to the status of the office. In turn, lending authority influenced the ranking of management jobs. At the same time, years served was a significant determinant of employee seniority and qualification to advance to higher ranked positions. This resulted in the frequent reshuffling of staff to match jobs and individual seniority.

The breakdown of this system commenced as organisations moved away from time-served seniority to more active human resource management. This broadened the range of candidates suitable for any promotion opportunity, reducing the need for relocation to fill vacancies. Independently, the organisation of work changed. The status of branch managers was reduced, both overall and in the differential between branches. Authority for business lending was transferred to sector specialists. A combination of automated processing and the centralised assessment of applications outside computerised evaluation reduced the branch discretion over personal lending. Centralisation of back-office functions reduced the range of jobs within branches and created a spatial concentration of employment within national or at least multi-regional customer service and processing centres.

Coincidentally, employee willingness to relocate reduced. The growth of dual income households is identified as a significant contributor to the change in attitude. It 
reduced mobility and raised expectations that relocation assistance would compensate the cost of the shift on a spouse's career. More recently, changes in work organisation have made branch management a more female occupation than previously. In turn, to the extent that careers of males exert a stronger influence on household decisions, the gender shift accentuated employee disinterest in relocation. Internal recruitment is still favoured for managerial positions but now relies on employee application and generates less movement than originally.

These types of change are typical of all organisations with a branch network, although with differences in sequencing and the relative importance of different processes. For example, in the case of physical goods distribution, the deregulation of road transport in the late 1980s produced a first round of organisation change as the number of regional depots was rationalised. More recently, information technology has increased capacity to centralise logistics management and enabled the physical concentration of warehousing.

In organisations without a sales or distribution network affected by the above processes, consolidation of control functions in Auckland has been the single main influence reducing relocation. The dominance of Auckland as a centre of employment and population is long established. Even so there has been ongoing opportunity for greater consolidation of corporate control functions in Auckland. When this occurs, it typically increases functional separation between Auckland-based activities and the rest of the country. The consequence is reduced scope for staff relocation. A second reason for employment consolidation in some organisations has been the externalisation of maintenance, logistics and other 'non core' functions. This has had a similar effect in reducing the coverage of internal labour markets in regional service centres.

Overseas ownership and the transfer of national control to regional offices outside New Zealand (typically Australia or Singapore) add a further level of organisational centralisation that depresses relocation. In the last five years, 11 organisations have shifted senior management and corporate positions to the regional head office. The loss of New Zealand head office functions has the immediate impact of relocating positions to the regional office. In one organisation, for example, this had resulted in the replacement of the national CEO by direct reporting to individual line managers in Australia. Data processing is another frequently centralised activity as well as human resource management. In the long term, the loss of national control can limit New Zealand to implementation and operational roles with less need or scope for employee mobility.

Diverse influences have reduced the frequency of organisational labour migration. A commitment to an internal labour market is a necessary condition for organisational labour migration. On the other hand, the survey suggests that the reduced importance of employee relocation is not simply an outcome of shifts in the relative status of internal and external labour markets. All organisations indicate a commitment to internal recruitment over external recruitment. A low rate of relocation is consistent with this commitment for three reasons.

First, most organisations have employment concentrated in one or two locations that facilitate internal appointments without relocation. Second, the commitment to internal recruitment is typically strongest in respect of positions that have low turnover. Third, the shift toward flatter managerial structures reduces the scope for promotion-linked moves.

The organisation generating most movement (over 400 moves annually among 7000 employees) shows the impact of these influences on relocation. Attributes producing its exceptional rate of movement include the following.

- The restriction of external recruitment to entrylevel positions and a policy of encouraging experience in different work locations as one of the qualifications for career advancement.

- Maintenance of multiple job grades, including formalised qualifications and experience requirements for career advancement.

- Nationally dispersed employment locations in which the region with the greatest concentration of employment (Auckland) does not disproportionately offer senior positions. This allows employees to advance their career in regional locations.

- High levels of vacancy for experienced staff as a consequence of organisational growth and the constraints on external recruitment.

In addition, four further influences particular to the organisation encourage relocation.

- A national rate of pay that effectively increases an employee's real wage outside of the main urban centres. This promotes an incentive to move to smaller centres. Movement increases because entry-level recruitment is highest in the main population centres, especially Auckland where vacancy rates are highest. Outside main centres, recruits typically wait for up to 12 months between selection and actual entry.

- Conditions of employment vary geographically. The higher rate of vacancy in Auckland increases work pressure compared with fullystaffed locations. Offsetting this, it can make Auckland an attractive location because of the possibility of more rapid advancement to senior levels.

- The workforce includes a comparatively high proportion of people with a spouse also 
employed by the organisation. This results in 'welfare moves' to follow a partner's relocation, estimated as around 20 percent of all relocations a year.

- The organisation is comparatively resource rich for expenditure on employee relocation partly as a consequence of having unfilled positions.

Work arrangements facilitated by new communications and information technology are not a significant influence on the frequency of relocation. In the two situations where it was of some importance the impact has been in reducing relocation. An organisation identifying that its workforce had become 'high tech' linked this to a reduced commitment to an internal labour market. The instability of skills in new technology-based activities reduced the organisation's willingness to provide employment continuity. To facilitate use of the external labour market, activities had been concentrated in Auckland.

The second example involved two organisations reliant on project-based work. The short-term nature of much engineering and business consulting work potentially gives rise to considerable instability in the distribution of employees. Information technology is said to be reducing this by enabling work to be distributed between work sites rather than being conducted close to the client. This has most impact in reducing the relocation of junior and mid grade staff. Customer relations and new business generation tends to be a large part of the responsibility of senior staff and this requires a location close to active clients.

\section{Movement in Detail}

A profile of recent employee relocations over a 12-month period was obtained from 15 organisations. A total of 910 employees were relocated by these organisations, amounting to almost two-thirds of the relocations identified in the larger sample. The organisations are of a similar size range to those in the larger sample but differ in being drawn from a narrow cross-section of industries (Table 5). Given that the 15 organisations account for slightly over half the moves identified among the 50 respondents in the main surkey, the sub-sample appears to include comparatively active movers. As explained in the discussion of relocation frequency, it is likely that they do not capture all employee-initiated moves, but this may equally effect the estimate in the main sample.

Employees relocated are predominantly male, have over five years of experience with the organisation and occupy non-senior managerial or skilled professional roles prior to being moved (Table 6). These characteristics are strongly dominant; except that staff with less than five year's experience are clearly not exempt from relocation opportunities. The profile is disproportionately influenced by one organisation that accounts for almost half of the relocations. Excluding this organisation, there is an almost equal proportion of male and female staff being relocated.

Table 5 Sector and size of the organisations supplying a profile of employee relocations $(n=15)$

\begin{tabular}{|l|c|c|c|}
\hline \multicolumn{1}{|c|}{ Sector } & $\begin{array}{c}\text { Share (\%) of } \\
\text { sample } \\
\text { employment }\end{array}$ & Employment range & $\begin{array}{c}\text { Number of } \\
\text { organisations }\end{array}$ \\
\hline Primary & 4 & over 5000 & 3 \\
Manufacturing & 3 & $2000-4999$ & 3 \\
Communications & 26 & $1000-1999$ & 2 \\
Finance & 23 & less than 1000 & 7 \\
Business services & 2 & & \\
Government & 20 & & \\
Community services & 18 & & \\
Other & 4 & & \\
\cline { 2 - 4 } & \multicolumn{2}{|l}{}
\end{tabular}

Table 6 Characteristics of employees relocated among 15 organisations

\begin{tabular}{|l|c|l|r|}
\hline \multicolumn{4}{|c|}{ Number of employees relocated } \\
\hline \multicolumn{3}{|c|}{ Years of service } & \multicolumn{2}{|c|}{ Job status prior to relocation } \\
\hline Less than 1 & $26(3 \%)$ & Senior manager & $83(9 \%)$ \\
$1-5$ & $214(24 \%)$ & Other manager or & $570(63 \%)$ \\
& $517(57 \%)$ & skilled professional & \\
Over 5 & $153(17 \%)$ & Other & $105(12 \%)$ \\
Unclassified & 910 & Unclassified & $153(17 \%)$ \\
\hline Total relocations & Share of total male & $600(66 \%)$ \\
\hline
\end{tabular}

Note: 1 . Senior managers defined as managers with responsibility for other managers. 
The geography of relocation within the sub-sample shows that Wellington and the South Island are net recipients of relocated staff while other parts of the North Island are net suppliers of staff (Table 7). The largest gross flows are into and out of Auckland and other North Island locations excluding Wellington. Overall, the data suggest how relocation achieves a circulation of staff between locations, as reflected in the small net flow compared with the total gross flow. The largest net flow indicates Auckland's role in supplying labour to regional locations.

Table 7 The geography of employee relocation among 15 organisations

\begin{tabular}{|l|c|c|c|}
\hline \multicolumn{4}{c|}{ Number of employees } \\
\hline \multicolumn{1}{|c|}{ Region } & Relocated from & Relocated to & Net flow \\
\hline Auckland & 261 & 212 & -49 \\
Wellington & 99 & 129 & +30 \\
Other North Island & 277 & 246 & -31 \\
Canterbury & 67 & 89 & +22 \\
Otago & 41 & 43 & +2 \\
Other South Island & 55 & 71 & +16 \\
\hline
\end{tabular}

\section{Implications of the Survey Findings}

The 2001 Census indicates that there are around 70,000 internal regional migrants a year (this total is limited to persons identifying a specific region of residence). Of these, around 77 percent or 53,700 are of working age (15-64). The present study identified almost 1500 organisational migrants among 50 employers. If this rate of relocation holds among the country's largest 100 multiregion employers, and these large employers account for most relocation, organisational labour migration would account for around 5.5 percent of gross regional migration a year by working-age people.

The relocation estimate takes no account of dependants moving with the relocated employee and potentially misses some employee-initiated relocation. It may also under-estimate relocation within smaller organisations. Allowing for these possibilities, organisational labour migration may account for 10-15 percent of all internal migration. Although a small aspect of migration numerically it is of greater significance in terms of the employment status of those moved.

Respondents indicate that the frequency of employee relocation has declined. In organisations with branch networks that have reduced significantly in employment, relocation is now perhaps half the level of 10 years ago.

Further investigation is required to identify the sequencing and overall importance of individual processes, but broadly five issues seem to have arrested and reversed the growth of organisational labour migration.

1. Changes in human resource management have reduced the influence of 'time served' as a determinant of seniority. This opens internal vacancies to a wider range of applicants than where seniority determines who is 'next in line' for the position. Competition for vacancies reduces relocation where it increases the ability to obtain recruits close to the vacancy.

2. In 'high tech' occupations, increased use of external labour markets has reduced organisational investment in an internal labour market.

3. The reduction of branch networks, centralisation of customer support and externalisation of service functions has tended to reduce regional employment within large organisations. This reduces the volume of relocation, both because of less opportunity and increased functional separation of the centre and branch establishments.

4. The growth of dual income households has reduced individual mobility where relocation impacts negatively on a working spouse. Organisations are generally unwilling to respond to this issue beyond referral of a spouse to an employment search agency. This is despite recognising that a move disadvantaging one working spouse is a risk to their employee's satisfaction with the move. It probably encourages employment concentration within large centres, so as to reduce employee turnover and maximise recruitment potential. It has encouraged employers to rely on voluntary relocation rather than directing it.

5. Regionalisation of management within transnational organisations reduces management positions within overseas territories. Where the overseas subsidiary's role is limited to implementation it tends to reduce the range occupations and employee relocation.

The New Zealand context probably accentuates the decline of organisational labour migration compared with larger industrial economies. The concentration of employment and national head offices in Auckland reduces the need for employee relocation. The high level 
of foreign ownership of multi-region employers reduces occupation diversity. Even so other influences identified as depressing employee relocation suggest that New Zealand's experience is not unique.

Directly organisational labour migration is small but it is one aspect of the larger influence of multi-regional organisations on internal migration. This influence includes job relocation and the facilitation of employeeinitiated moves. At the same time it reinforces the differential mobility of employees who are assisted by an employer to migrant and those who are not.

\section{References}

Bedford, R. and Goodwin, J. (1997) Migration and urban population change: a preliminary analysis of the 1996 Census data, Briefing Paper 6. Migration Study Group, Population Studies Centre, University of Waikato, Department of Geography.

Business Demography Database (2001) Statistics New Zealand: Wellington.

Cappelli, P. (1999) The New Deal at Work. Harvard Business School Press: Boston.

Choy, W.K., Maré, D. and Mawson, P. (2002) Modelling regional labour market adjustment in New Zealand, Treasury Working Paper 02/01. New Zealand Treasury: Wellington.

Carroll, N., Hyslop, D., Maré, D., Timmins, J. and Wood, J. (2002) The turbulent labour market, Paper presented at the New Zealand Association of Economists' Conference in Wellington, 25-27 June 2002.

\section{Acknowledgements}

The project arose from financial support jointly awarded to the New Zealand Treasury and Department of Labour from the Departmental Contestable Research Pool, Ministry of Research Science and Technology. Natasha McMillan provided research assistance. The author is solely responsible fon the use of the data and its interpretation in this paper.

McKay, J. and Whitelaw, J. (1977) The role of large private and government organisations in generating flows of inter-regional migrants: the case of Australia. Economic Geography, 53, 2844.

New Zealand Management (2001) Top 200 New Zealand companies, New Zealand Management, December

Poot, J. (1986) A system approach to modelling the interurban exchange of workers in New Zealand. Scottish Journal of Political Economy, 33, 249274.

Salt, J. (1990) Organisational labour migration: theory and practice in the United Kingdom, in Johnson, J and Salt, J. (eds) Labour Migration the Internal Geographical Mobility of Labour in the Developed World, David Fulton, London

State Services Commission (2001) Human Resource Capability Survey of Public Service Departments as at 30 June 2001, State Services Commission, Wellington 